\title{
Isotopic Mass-Dependence of Metal Cation Diffusion Coefficients in Liquid Water
}

Ian C. Bourg ${ }^{1,2,3 *}$, Frank M. Richter ${ }^{2}$, John N. Christensen ${ }^{1}$ and Garrison Sposito ${ }^{1}$

${ }^{1}$ Geochemistry Department, Earth Sciences Division, Lawrence Berkeley National Laboratory, Berkeley, CA 94720

${ }^{2}$ Department of the Geophysical Sciences, The University of Chicago, Chicago, IL 60637

${ }^{3}$ Department of Earth and Planetary Sciences, Harvard University, Cambridge, MA 02138

*To whom correspondence should be addressed. E-mail: icbourg@lbl.gov 


\begin{abstract}
Isotope distributions in natural systems can be highly sensitive to the mass $(\mathrm{m})$ dependence of solute diffusion coefficients $(D)$ in liquid water. Isotope geochemistry studies routinely have assumed that this mass dependence either is negligible (as predicted by hydrodynamic theories) or follows a kinetic-theory-like inverse square root relationship $\left(D \propto m^{-0.5}\right)$. However, our recent experimental results and molecular dynamics (MD) simulations showed that the mass dependence of $D$ is intermediate between hydrodynamic and kinetic theory predictions $\left(D \propto m^{-\beta}\right.$ with $0 \leq \beta<0.2$ for $\mathrm{Li}^{+}$, $\mathrm{Cl}^{-}, \mathrm{Mg}^{2+}$, and the noble gases). In this paper, we present new MD simulations and experimental results for $\mathrm{Na}^{+}, \mathrm{K}^{+}, \mathrm{Cs}^{+}$, and $\mathrm{Ca}^{2+}$ that confirm the generality of the inverse power-law relation $D \propto m^{-\beta}$. Our new findings allow us to develop a general description of the influence of solute valence and radius on the mass dependence of $D$ for monatomic solutes in liquid water. This mass dependence decreases with solute radius and with the magnitude of solute valence. Molecular-scale analysis of our MD simulation results reveals that these trends derive from the exponent $\beta$ being smallest for those solutes whose motions are most strongly coupled to solvent hydrodynamic modes.
\end{abstract}




\section{INTRODUCTION}

Despite nearly a century of research, the relationship between molecular-scale properties (mass, charge, and ion-solvent interactions) and the diffusion coefficients of solutes in liquid water is not fully understood (Koneshan et al., 1998a; Yamaguchi et al., 2005; Møller et al., 2005). In particular, the influence of isotopic mass ( $m$ ) on diffusion coefficients $(D)$ has gone essentially unexamined, with most theoretical models assuming that $D$ is simply independent of $m$ (Wolynes, 1978; Wilson et al., 1985; Berkowitz and Wan, 1987; Biswas and Bagchi, 1997; Chong and Hirata, 1998). However, a mass dependence of $D$ has long been recognized in isotope geochemistry (Desaulniers et al., 1986; Pernaton et al., 1996) where methods for reconstructing paleoclimate (Peeters et al., 2002; Gussone et al., 2003; Bourg and Sposito, 2008), inferring groundwater hydrology (Lavastre et al., 2005; Bourg and Sposito, 2008; LaBolle et al., 2008) or biogeochemical fluxes (Donahue et al., 2008; Bourg, 2008), and detecting natural gas resources (Prinzhofer and Pernaton, 1997; Schloemer and Krooss, 2004) can be sensitive to small $\left(<1 \%\right.$ ) differences in mass dependence for aqueous solutes such as $\mathrm{Ca}^{2+}, \mathrm{Cl}^{-}$, $\mathrm{CH}_{4}$, or the noble gases. In the absence of independent estimates of this mass dependence, isotope geochemistry studies routinely have assumed that $D$ has either a negligible mass dependence (Chernyasvsky and Wortmann, 2007) or a kinetic-theory-like inverse square-root dependence on solute mass (Peeters et al., 2002; Appelo and Postma, 2005; Donahue et al., 2008), solute-solvent reduced mass $\left[\mu=m m_{0} /\left(m+m_{0}\right), m_{0}\right.$ being either the molecular mass of the solvent (LaBolle et al., 2008)], or the "effective mass" of the solvation complex $\left[m_{\mathrm{eff}}=m+n m_{0}, n\right.$ being the number of solvent molecules in the solvation complex (Gussone et al., 2003)]. 
Recently we showed experimentally (Richter et al., 2006) that the diffusion coefficients of $\mathrm{Li}$ and $\mathrm{Cl}$ isotopes in liquid water are inversely related to their isotopic mass: $D\left({ }^{7} \mathrm{Li}^{+}\right) / D\left({ }^{6} \mathrm{Li}^{+}\right)=0.99772 \pm 0.00026$ and $D\left({ }^{37} \mathrm{Cl}^{-}\right) / D\left({ }^{35} \mathrm{Cl}^{-}\right)=0.99857 \pm 0.00080$, whereas that of $\mathrm{Mg}$ is independent of isotopic mass [i.e., $D\left({ }^{25} \mathrm{Mg}^{2+}\right) / D\left({ }^{24} \mathrm{Mg}^{2+}\right)=1.00003$ $\pm 0.00006]$. Our follow-up molecular dynamics (MD) simulations of solute diffusion in liquid water (Bourg and Sposito, 2007, 2008) confirmed that the mass dependence of $D$ has an inverse power-law form suggested by Richter et al. (2006),

$$
D \propto m^{-\beta}, \quad(0 \leq \beta<0.2)
$$

for $\mathrm{Li}^{+}, \mathrm{Cl}^{-}, \mathrm{Mg}^{2+}$ (Bourg and Sposito, 2007) and the noble gases (Bourg and Sposito, 2008 ), with predicted $\beta$-values consistent with those derived from experimental $D$-ratios and, more broadly, in agreement with results for diffusion in simple fluids (Bhattacharyya and Bagchi, 2000; Willeke, 2003) and molten solids (Tsuchiyama et al., 1994; Richter et al., 2003; Watkins et al., 2009). In the present paper, we extend these findings with new MD simulations and experimental results on the mass-dependence of $D$ for alkali metal and alkaline earth cations, species that are of signal importance in both ion diffusion theory (Impey et al., 1983; Koneshan et al., 1998a,b; Chong and Hirata, 1999; Chowdhuri and Chandra, 2003; Yamaguchi et al., 2005; Ghorai and Yashonath, 2006) and isotope geochemistry (Gussone et al., 2003; DePaolo, 2004; Teng et al., 2006). Our new results allow us to develop a general description of the influence of solute radius and valence on the isotopic mass dependence of $D$ for monatomic solutes in liquid water. 


\section{Molecular Dynamics Simulations}

We performed MD simulations for $\mathrm{Na}^{+}, \mathrm{K}^{+}, \mathrm{Cs}^{+}$, and $\mathrm{Ca}^{2+}$ (one solute and 550 water molecules in a periodically-replicated simulation cell, NVE ensemble) at $348 \mathrm{~K}$ using our previous methodology (Bourg and Sposito, 2007, 2008), in which the diffusive behavior of a range of hypothetical isotopes of these cations $(m=2-133 \mathrm{Da})$ is analyzed. [The temperature of $348 \mathrm{~K}$ was chosen to facilitate our isotope fractionation measurements (Richter et al., 2006). Temperature has no influence on the mass-dependence of $D$ between 298 and $348 \mathrm{~K}$ within the precision of simulation or experimental methods (Bourg and Sposito, 2007; Eggenkamp and Coleman, 2009).] Simulations with the major isotope of each solute were carried out at density $\rho=0.975 \mathrm{~kg} \mathrm{dm}^{-3}$; simulation cell volume was identical for all isotopes of each solute. Simulation times were $8 \mathrm{~ns}$ for alkali metal cations and $16 \mathrm{~ns}$ for $\mathrm{Ca}^{2+}$, both preceded by a 202 ps equilibration. Diffusion in liquid water is usually probed over much shorter time scales $[\leq 1.0 \mathrm{~ns}$ (Smith and Dang, 1994; Koneshan et al., 1998b; Yamaguchi et al., 2005; Ghorai and Yashonath, 2006)]; our studies show, however, that $D$ values can vary by up to $24 \%$ during successive $2 \mathrm{~ns}$ intervals in a MD simulation. Molecular trajectories were calculated by solving the Newton-Euler equations ( $1 \mathrm{fs}$ time step) with a form of the Beeman algorithm, one of the most accurate Verlet-equivalent algorithms (Refson, 2000). Excellent conservation of energy $[<0.02 \%$ total energy drift over $8 \mathrm{~ns}$ simulation time (Bourg and Sposito, 2007)] allowed us to run our long simulations without coupling our simulation cell to an artificial thermostat. Interatomic forces were described with the extended simple point charge (SPC/E) model (Berendsen et al., 1987) and associated solute-water interaction models (Åqvist, 1990; Dang, 1995). This set of interatomic 
potential models, known to accurately describe the coordination and diffusion of water and cations in liquid water (Åqvist, 1990; Smith and Dang, 1994; Dang, 1995;

Wasserman et al., 1995; Koneshan et al., 1998b; Hura et al., 2003), has been used in a number of studies of cation diffusion in liquid water (Koneshan et al., 1998a,b; Chong and Hirata, 1999; Chowdhuri and Chandra, 2003; Yamaguchi et al., 2005). Solute diffusion coefficients $D$ were calculated from velocity autocorrelation functions $C_{\mathrm{V}}(\mathrm{t})$ using the appropriate Green-Kubo relation (Frenkel and Smit, 2002). Our predictions of $D_{i} / D_{j}$ ratios for the major isotopes of $\mathrm{Li}^{+}$(Bourg and Sposito, 2007), $\mathrm{Na}^{+}, \mathrm{K}^{+}, \mathrm{Cs}^{+}$, and $\mathrm{Ca}^{2+}$ were consistent with experimental $D_{i} / D_{j}$ values obtained by extrapolating measured limiting ionic conductivities (Robinson and Stokes, 1959) to $348 \mathrm{~K}$ using the well-known Arrhenius and Nernst-Einstein relations. All alkali metal cation $D$-values showed an inverse power-law mass dependence (Fig. 1), as we previously reported for $\mathrm{Li}^{+}, \mathrm{Cl}^{-}$ (Richter et al., 2006; Bourg and Sposito, 2007), and noble gases (Bourg and Sposito, 2008), whereas $D\left(\mathrm{Ca}^{2+}\right)$ had no resolvable mass dependence, as we previously reported also for $\mathrm{Mg}^{2+}$ (Richter et al., 2006; Bourg and Sposito, 2007). For comparison, simulation and experimental results are reported in Table 1 as values of the power-law exponent $\beta$.

\section{DIFFUSION MEASUREMENTS}

In parallel with our MD simulations, we acquired new experimental data on $\mathrm{K}^{+}$and $\mathrm{Ca}^{2+}$ isotope fractionation by diffusion in liquid water at $348 \mathrm{~K}$ using the methods developed by Richter et al. (2006). A small glass sphere with a volume $V_{\mathrm{s}} \approx 0.6 \mathrm{~cm}^{3}$ was filled with a salt solution having a nominal concentration of 0.1 molar $\mathrm{KCl}$ or $\mathrm{CaCl}_{2}$. A cylindrical 
tube (length $L \approx 1 \mathrm{~cm}$, cross-sectional area $A \approx 0.03 \mathrm{~cm}^{2}$ ) allowed the salt to diffuse from the sphere to an outer container initially filled with a volume $V_{\mathrm{c}} \approx 250 \mathrm{~cm}^{3}$ of pure water. The dimensions of the sphere and the diffusion tube were chosen such that the salt concentration in the source sphere remains spatially uniform during the experiments. Potassium and $\mathrm{Ca}$ isotopic compositions in the source sphere and outer container, measured as described in the following section, are reported as $1000 \ln \left(R_{i j} / R_{i j, 0}\right)$ vs. $-\ln f_{j}$ (Fig. 2), where $R_{i j}$ and $R_{i j, 0}$ are the $i j$ isotopic ratio at times $t$ and $t=0$ and $f_{j}$ is the fraction of component $j$ remaining in the source flask at time $t$.

As shown by Richter et al. (2006), elemental and isotopic ratios $R_{i j}$ in the source sphere and outer container are determined by the ratio of the diffusion coefficients of components $i$ and $j\left(D_{i} / D_{j}\right)$ and by the ratio of container volumes $\left(V_{\mathrm{c}} / V_{\mathrm{s}}\right)$. The solid lines in Fig. 2 were obtained with $V_{\mathrm{c}} / V_{\mathrm{s}}=375$ and then fitted to the data by choosing $D_{i} / D_{j}$ ratios. At short times, when the salt concentration in the outer container is negligible compared to that in the source sphere, $R_{i j}$ in the source sphere can be expressed simply by a Rayleigh fractionation equation:

$$
\ln \left(R_{i j} / R_{i j, 0}\right)=\left(D_{i} / D_{j}-1\right) \times \ln f_{j} .
$$

At large times, when the concentration in the outer container is no longer negligible compared to that in the source chamber $\left(-\ln f_{j}>\sim 3.5\right.$ in Fig. 2), isotopic fractionation decreases and eventually goes to zero as the source flask and outer container equilibrate. The chloride counterions present in our experimental systems should not affect the ratio $D_{i} / D_{j}$ unless contact ion pairs are much more prevalent in $\mathrm{KCl}$ and $\mathrm{CaCl}_{2}$ than in $\mathrm{LiCl}$ and $\mathrm{MgCl}_{2}$ electrolytes (Richter et al., 2006; Bourg and Sposito, 2007). The measured depletion of ${ }^{41} \mathrm{~K}$ relative to ${ }^{39} \mathrm{~K}$ in the outer container (lower part of Fig. 2a) is consistent 
with the ratio for the diffusivity of the $\mathrm{K}$ isotopes determined by the data from the source flask (upper part of Fig. 2a). For Ca (Fig. 2b), the depletion of ${ }^{44} \mathrm{Ca}$ relative to ${ }^{40} \mathrm{Ca}$ in the outer container was too small to measure precisely, and isotopic ratios in the source chamber scatter around calculated evolution curves by amounts that are large compared to the internal analytical precision of the isotopic measurements. Regardless of the scatter, however, there is a resolvable fractionation of $\mathrm{Ca}$ isotopes.

\section{PotASSIUM AND CALCIUM ISOTOPIC MEASUREMENTS}

Potassium isotopic measurements were carried out with a multiple-collector ICP source magnetic sector mass spectrometer (IsoProbe by GV Instruments). The IsoProbe features a RF only hexapole ion guide, in which various gases (e.g. $\mathrm{He}, \mathrm{H}_{2}, \mathrm{Ne}$, Ar) can be dynamically introduced. In the case of the ${ }^{41} \mathrm{~K} /{ }^{39} \mathrm{~K}$ measurements reported here, Ne and $\mathrm{H}_{2}$ were used in the hexapole to provide energy focusing as well as to remove Ar ion species. A positive potential was applied to the extraction lens to suppress secondary discharge and avoid memory effects from the skimmer and extraction cones. A static beam measurement was used with three of the nine available Faraday collectors set to simultaneously collect masses 39, 40, and 41 (Axial, H1, H2, respectively). Our measurement routine included peak blank subtraction from the measured ion beams. Twenty cycles of data were collected with an integration time of 5 seconds, for a total process time of about four minutes. Sample solutions were introduced to the IsoProbe using a desolvation nebulization system (Aridus II, Cetac Technologies) and a teflon nebulizer with a $60 \mu \mathrm{L} / \mathrm{min}$ uptake rate. Sample solutions were prepared from dried aliquots in $2 \% \mathrm{HNO}_{3}$ to matching $\mathrm{K}$ concentrations of $300 \mathrm{ppb}$. Analysis runs of the 
experimental solutions were bracketed with runs of the starting $\mathrm{KCl}$ solution. Approximately $120 \mathrm{ng}$ of $\mathrm{K}$ was used per isotopic analysis run. Reproducibility of the ${ }^{41} \mathrm{~K} /{ }^{39} \mathrm{~K}$ values was on the order of $\pm 0.25 \%$ ( $(2 \sigma)$.

Calcium isotopic measurements were carried out by thermal ionization mass spectrometry with a Triton (Thermo-Finnigan) multicollector instrument using a doublespike technique. Aliquots of the sample solutions representing between 5 and 20 micrograms were spiked with a ${ }^{42} \mathrm{Ca}-{ }^{48} \mathrm{Ca}$ double spike, equilibrated, and dried, then approximately $5 \mu \mathrm{g}$ were loaded onto one filament of a double filament assembly. Samples were run with currents of 1.8-2.0 amps on the evaporation (sample) filament and 3 amps on the ionization filament, yielding a target ${ }^{40} \mathrm{Ca}$ ion beam of 20 volts $\left(2 \times 10^{-10}\right.$ amps). A multi-dynamic Faraday cup routine was used to collect the Ca isotopic data, with $\mathrm{K}$ and $\mathrm{Ti}$ isobaric interferences monitored with a secondary electron multiplier ioncounting system. Reproducibility of the ${ }^{44} \mathrm{Ca} /{ }^{40} \mathrm{Ca}$ values was on the order of $\pm 0.25 \%$ $(2 \sigma)$.

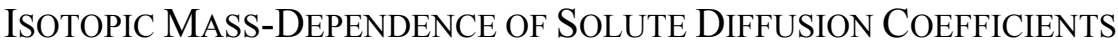

Within the ability of our MD simulations to resolve isotopic mass dependence, there is agreement between the $\beta$-values obtained experimentally and those obtained by MD simulation for $\mathrm{K}^{+}$and $\mathrm{Ca}^{2+}$, as well as for $\mathrm{Li}^{+}, \mathrm{Cl}^{-}, \mathrm{Mg}^{2+}$ (Bourg and Sposito, 2007) and $\mathrm{Na}^{+}$(Pikal, 1972) (Table 1). The most significant result is for $\mathrm{K}^{+}$, where both the MD predictions and confirming experimental results show isotope fractionation significantly greater than the uncertainties. This overall agreement between simulated and measured $\beta$ values supports the conclusion that the diffusion coefficients of most monatomic solutes 
have a mass dependence that is significant [in contradiction with extant theories of solute diffusion in liquid water (Wolynes, 1978; Wilson et al., 1985; Berkowitz and Wan, 1987; Biswas and Bagchi, 1997; Chong and Hirata, 1998)], yet much smaller than predicted by the kinetic-theory-like "square root" models frequently used in isotope geochemistry (Appelo and Postma, 2005; Donahue et al., 2008; LaBolle et al., 2008).

A plot of $\beta$ vs. solute radius $r$ (Fig. 3) summarizes our findings on the isotopic massdependence of $D$ for monatomic solutes in liquid water. Shaded areas in Fig. 3 highlight the size-dependence of $\beta$ for uncharged, monovalent, and divalent solutes. The clearest trend in Fig. 3 is the existence of an inverse relationship between $\beta$ and the magnitude of solute valence ( $\beta \sim 0.00-0.01$ for divalent ions, $\beta \sim 0.01-0.06$ for monovalent ions, $\beta \sim$ $0.05-0.19$ for the noble gases). This valence dependence of $\beta$ is consistent with the expectation that dissolved gases inherently behave in a more "gas-like" (i.e., kinetictheory-like) manner than do ionic solutes. The similar behavior of $\mathrm{Cs}^{+}$and $\mathrm{Cl}^{-}$shows that $\beta$ is not strongly affected by the sign of solute valence.

A second clear trend in Fig. 3 is that $\beta$ decreases with solute radius $r$ for the noble gases and for large monovalent ions. This behavior is consistent with the expectation that infinitely large (Brownian) solutes should follow the hydrodynamic-theory prediction, $\beta$ $=0\left(\right.$ Willeke, 2003). The small monovalent ions $\mathrm{Li}^{+}$and $\mathrm{Na}^{+}$contradict this general inverse size dependence of $\beta$. As shown in the following section, the size dependence of $\beta$ for monovalent ions mirrors the size dependence of the solvation dynamics of these ions: large $\left(\mathrm{Cl}^{-}\right)$and small $\left(\mathrm{Li}^{+}, \mathrm{Na}^{+}\right)$monovalent ions have more stable solvation shells than does the intermediate-sized $\mathrm{K}^{+}$ion. 


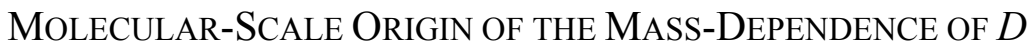

To gain mechanistic insight into the mass dependence of $D$, we calculated a conventional memory function $K(t)\left[D=k_{\mathrm{B}} T / \zeta\right.$ and $\zeta=\int_{0}^{\infty} K(t) d t$, where $\zeta$ is the static friction coefficient], for hypothetical isotopes of $\mathrm{Li}^{+}, \mathrm{Na}^{+}, \mathrm{K}^{+}$, and $\mathrm{Cs}^{+}$from our MD simulation results by iteratively solving the standard relationship (Ohmori and Kimura, 2005):

$$
K(t)=-\frac{1}{C_{\mathrm{V}}(0)}\left[m \frac{\partial^{2} C_{\mathrm{V}}(t)}{\partial t^{2}}+\int_{0}^{t} K(t-\tau) \frac{\partial C_{\mathrm{V}}(t)}{\partial t} d \tau\right] .
$$

Our results [illustrated in Fig. 4 as plots of $K(t)$ vs. $\log t$ for five isotopes of potassium] are consistent with a decomposition of $K(t)$ into a short-time, Gaussian-like binarycollision component (at $t<0.05 \mathrm{ps)}$ and a long-time hydrodynamic component (Chong and Hirata, 1999; Ohmori and Kimura, 2005). They show, apparently for the first time, that the binary-collision component of $K(t)$ relaxes more rapidly for light isotopes; i.e., the "rattling motions" of light ions in their solvation cages hasten the relaxation of shorttime ion-solvent interactions (Yamaguchi et al., 2005; Møller et al., 2005).

If we model the friction coefficient as the sum of a short-time binary-collision component and a long-time hydrodynamic component $\left(\zeta \equiv \zeta_{\text {fast }}+\zeta_{\text {slow }}\right)$, a Gaussian fit to the short-time behavior of $K(t)$ (Chong and Hirata, 1999) yields $\zeta_{\text {fast }} \propto \mu^{0.3}$ for the alkali metal cations, where $\mu$ is the reduced mass of the cation- $\mathrm{H}_{2} \mathrm{O}$ pair. Thus, two competing effects determine the isotopic mass dependence of $D$ : short-time $(<0.05 \mathrm{ps})$ collisiondominated friction $\zeta_{\text {fast }}$, with a strong, kinetic-theory-like mass dependence, and longtime $(0.05-2.5 \mathrm{ps})$ hydrodynamic friction $\zeta_{\text {slow }}$, which strongly attenuates any mass dependence of $\zeta$. The mass dependence of $D$ should therefore be weak if hydrodynamic modes contribute dominantly to $\zeta$. This latter condition may occur either because of a 
large solute radius (thus $\beta_{\mathrm{Cl}}<\beta_{\mathrm{K}}$ and $\beta_{\mathrm{Xe}}<\beta_{\mathrm{He}}$, Fig. 3) or because of a strong solutesolvent attractive interaction (thus $\beta_{\mathrm{Li}}<\beta_{\mathrm{K}}$ and $\beta_{\text {divalent_ion }}<\beta_{\text {monovalent_ion }}<\beta_{\text {noble_gas, }}$ Fig. $3)$.

A molecular-scale property that expresses the long-time coupling of solute and solvent motions is the average residence time $\tau_{\mathrm{S}}$ of water molecules in the first solvation shell of the solute (Bourg and Sposito, 2007). We calculated this property for $\mathrm{Mg}^{2+}$, $\mathrm{Ca}^{2+}, \mathrm{Li}^{+}, \mathrm{Na}^{+}, \mathrm{K}^{+}, \mathrm{Cs}^{+}, \mathrm{Cl}^{-}$and the noble gases at $298 \mathrm{~K}$ (from $2 \mathrm{~ns}, N V E$ ensemble $\mathrm{MD}$ simulations with one solute and 550 water molecules per simulation cell) as described by Koneshan et al. (1998b) (Table 2). A plot of experimental and MD simulation $\beta$-values vs. $1 / \tau_{\mathrm{S}}$ (Fig. 5) shows that $\beta$ is inversely related to $\tau_{\mathrm{S}}$, as expected from the previous paragraph. [Linear regression of the MD simulation data in Fig. 5 yielded $R^{2}=0.94$, whereas plots of $\beta$ against first-shell coordination number $n_{\mathrm{O}}$ or solute-water distance $r_{\max }$ (Table 2) yielded $R^{2} \leq 0.35$, which is not statistically significant $(\mathrm{P}=0.05)$.] Essentially, a greater residence time $\tau_{\mathrm{S}}$ allows more collisions of the solute with each water molecule, thus rendering the diffusion of the solute less kinetic-theory-like (Bourg and Sposito, 2007).

\section{CONCLUSIONS}

Our experimental results and molecular dynamics simulations show that the diffusion coefficients of monatomic solutes in liquid water have an inverse power-law mass dependence $\left(D \propto m^{-\beta}\right)$ with $0 \leq \beta<0.2$, in clear contradiction with diffusion theories routinely applied in geochemical modeling (Appelo and Postma, 2005; Chernyavsky and Wortmann, 2007; Donahue et al., 2008; LaBolle et al., 2008). This finding has important 
implications for geochemical interpretations of isotope distributions in diffusion-limited hydrologic systems (Schloemer and Krooss, 2004; Lavastre et al., 2005; Bourg, 2008; Bourg and Sposito, 2008).

Molecular-scale analysis shows that the mass dependence of $D$ is greatest for solutes whose motions are the most weakly coupled to solvent hydrodynamic modes, as illustrated by the inverse relationship between $\beta$ and the average residence time $\tau_{\mathrm{S}}$ of water molecules in the first solvation shell of the diffusing solute. From a geochemical perspective, our results further suggest that, if nano-confinement attenuates hydrodynamic modes, isotope fractionation may be enhanced in water-filled nanopores, an effect already apparent in available data on $\mathrm{CH}_{4}$ diffusion in smectite clays (Pernaton et al., 1996) vs. sandstone (Schloemer and Krooss, 2004) and on $\mathrm{Li}^{+}$diffusion in dialysis membranes (Fritz, 1992) or grain boundaries (Teng et al., 2006) vs. bulk liquid water (Richter et al., 2006).

\section{Acknowledgments}

The research reported in this paper was supported by the Director, Office of Energy Research, Office of Basic Energy Sciences, of the U.S. Department of Energy under Contract Nos. DE-AC02-05CH11231 (ICB/JNC/GS) and DE-FG02-01ER15254 (ICB/FMR). This research also was supported by the National Science Foundation through TeraGrid resources provided by the San Diego Supercomputer Center. The authors are grateful to Professor R.E. Zeebe and two anonymous reviewers for helpful comments on the manuscript. 


\section{References}

Appelo C.A.J. and Postma D. (2005) Geochemistry, Groundwater and Pollution, $2^{\text {nd }}$ Ed., Balkema.

Åqvist J. (1990) Ion-water interaction potentials derived from free Energy perturbation simulations. J. Phys. Chem. 94, 8021-8024.

Berendsen H.J.C., Grigera J.R. and Straatsma T.P. (1987) The missing term in effective pair potentials. J. Phys. Chem. 91, 6269-6271.

Berkowitz M. and Wan W. (1987) The limiting ionic conductivity of $\mathrm{Na}^{+}$and $\mathrm{Cl}^{-}$ions in aqueous solutions: Molecular dynamics simulation. J. Chem. Phys. 86, 376-382.

Bhattacharyya S. and Bagchi B. (2000) Power law mass dependence of diffusion: A mode coupling theory analysis. Phys. Rev. E 61, 3850-3856.

Biswas R. and Bagchi B. (1997) Limiting ionic conductance of symmetical, rigid ions in aqueous solutions: Temperature dependence and solvent isotope effects. J. Am.

Chem. Soc. 119, 5946-5953.

Bourg I.C. and Sposito G. (2007) Molecular dynamics simulations of kinetic isotope fractionation during the diffusion of ionic species in liquid water. Geochim. Cosmochim. Acta 71, 5583-5589.

Bourg I.C. (2008) Comment on "Modeling sulfur isotope fractionation and differential diffusion during sulfate reduction in sediments of the Cariaco Basin” by M.A. Donahue, J.P. Werne, C. Meile and T.W. Lyons. Geochim. Cosmochim. Acta 72, $5852-5854$. 
Bourg I.C. and Sposito G. (2008) Isotopic fractionation of noble gases by diffusion in liquid water: Molecular dynamics simulations and hydrologic applications. Geochim. Cosmochim. Acta 72, 2237-2247.

Chakrabarti H. (1995) Strong evidence of an isotope effect in the diffusion of a $\mathrm{NaCl}$ and CsCl solution. Phys. Rev. B 51, 12809-12812.

Chernyavsky B.M. and Wortmann U.G. (2007) REMAP: a reaction transport model for isotope ratio calculations in porous media. Geochem. Geophys. Geosyst. 8 , Q02009.

Chong S.-H. and Hirata F. (1998) Dynamics of solvated ion in polar liquids: An interaction-site-model description. J. Chem. Phys. 108, 7339-7349.

Chong S.-H. and Hirata F. (1999) Dynamics of ions in liquid water: An interaction-sitemodel description. J. Chem. Phys. 111, 3654-3667.

Chowdhuri S. and Chandra A. (2003) Hydration structure and diffusion of ions in supercooled water: Ion size effects. J. Chem. Phys. 118, 9719-9725.

Dang L.X. (1995) Mechanism and thermodynamics of ion selectivity in aqueous solutions of 18-crown-6 ether: A molecular dynamics study. J. Am. Chem. Soc. 117, 6954-6960.

DePaolo D.J. (2004) Calcium isotopic variations produced by biological, kinetic, radiogenic and nucleosynthetic processes. Rev. Miner. Geochem. 55, 255-288.

Desaulniers D.E., Kaufmann R.S., Cherry J.A. and Bentley H.W. (1986) 37Cl-35Cl variations in a diffusion-controlled groundwater system. Geochim. Cosmochim. Acta 50, 1757-1764. 
Donahue M.A., Werne J.P., Meile C. and Lyons T.W. (2008) Modeling sulfur isotope fractionation and differential diffusion during sulfate reduction in sediments of the Cariaco Basin. Geochim. Cosmochim. Acta 72, 2287-2297.

Eggenkamp H.G.M. and Coleman M.L. (2009) The effect of aqueous diffusion on the fractionation of chlorine and bromine stable isotopes. Geochim. Cosmochim. Acta 73, 3539-3548.

Frenkel D. and Smit B. (2002) Understanding Molecular Simulation, $2^{\text {nd }}$ Ed., Academic Press, San Diego.

Fritz S.J. (1992) Measuring the ratio of aqueous diffusion coefficients between ${ }^{6} \mathrm{Li}^{+} \mathrm{Cl}^{-}$ and ${ }^{7} \mathrm{Li}^{+} \mathrm{Cl}^{-}$by osmometry. Geochim. Cosmochim. Acta 56, 3781-3789.

Ghorai P.Kr. and Yashonath S. (2006) Evidence in support of levitation effect as the reason for size dependence of ionic conductivity in water: A molecular dynamics simulation. J. Phys. Chem. B 110, 12179-12190.

Gussone N., Eisenhauer A., Heuser A., Dietzel M., Bock B., Böhm F., Spero H.J., Lea D.W., Bijma J. and Nägler T.F. (2003) Model for kinetic effects on calcium isotope fractionation $\left(\delta^{44} \mathrm{Ca}\right)$ in inorganic aragonite and cultured planktonic foraminifera. Geochim. Cosmochim. Acta 67, 1375-1382.

Hura G., Russo D., Glaeser R.M., Head-Gordon T., Krack M. and Parrinello M. (2003) Water structure as a function of temperature from X-ray scattering experiments and ab initio molecular dynamics. Phys. Chem. Chem. Phys. 5, 1981-1991.

Impey R.W., Madden P.A. and McDonald I.R. (1983) Hydration and mobility of ions in solution. J. Phys. Chem. 87, 5071-5083. 
Koneshan S., Lynden-Bell R.M. and Rasaiah J.C. (1998a) Friction coefficient of ions in aqueous solution at $25^{\circ} \mathrm{C} . \mathrm{J}$. Am. Chem. Soc. 120, 12041-12050.

Koneshan S., Rasaiah J.C., Lynden-Bell R.M. and Lee S.H. (1998b) Solvent structure, dynamics, and ion mobility in aqueous solutions at $25^{\circ} \mathrm{C} . J$. Phys. Chem. B 102, 4193-4204.

Kunze R.W. and Fuoss R.M. (1962) Conductance of the alkali halides. III. The isotopic lithium chlorides. J. Phys. Chem. 66, 930-931.

LaBolle E.M., Fogg G.E., Eweis J.B., Gravner J. and Leaist D.G. (2008) Isotopic fractionation by diffusion in groundwater. Water Resour. Res. 44, W07405.

Lavastre V., Jendrzejewski N., Agrinier P., Javoy M. and Evrard M. (2005) Chlorine transfer out of a very low permeability clay sequence (Paris Basin, France): ${ }^{35} \mathrm{Cl}$ and ${ }^{37} \mathrm{Cl}$ evidence. Geochim. Cosmochim. Acta 69, 4949-4961.

Møller K.B., Rey R., Masia M. and Hynes J.T. (2005) On the coupling between molecular diffusion and solvation shell exchange. J. Chem. Phys. 122, 114508.

Ohmori T. and Kimura Y. (2005) Molecular dynamics for hydrophobic solutes in water from ambient to supercritical conditions. In Proc. $14^{\text {th }}$ Int. Conf. Propert. Water \& Steam, M. Nakahara et al. (Eds.), Maruzen Co, Ltd, pp 160-165.

Peeters F., Beyerle U., Aeschbach-Hertig W., Holocher J., Brennwald M.S. and Kipfer R. (2002) Improving noble gas based paleoclimate reconstruction and groundwater dating using ${ }^{20} \mathrm{Ne} /{ }^{22} \mathrm{Ne}$ ratios. Geochim. Cosmochim. Acta 67, 587-600.

Pernaton E., Prinzhofer A. and Schneider F. (1996) Reconsideration of methane signature as a criterion for the genesis of natural gas: influence of migration on isotopic signature. Rev. IFP 51, 635-651. 
Pikal M.J. (1972) Isotope effect in tracer diffusion. Comparison of the diffusion coefficients of ${ }^{24} \mathrm{Na}^{+}$and ${ }^{22} \mathrm{Na}^{+}$in aqueous electrolytes. J. Phys. Chem. 76, 30383040.

Prinzhofer A. and Pernaton E. (1997) Isotopically light methane in natural gas: bacterial imprint or diffusive fractionation? Chem. Geol. 142, 193-200.

Refson K. (2000) Moldy: a portable molecular dynamics simulation program for serial and parallel computers. Comput. Phys. Commun. 126, 310-329.

Richter F.M., Davis A.M., DePaolo D.J. and Watson E.B. (2003) Isotope fractionation by chemical diffusion between molten basalt and rhyolite. Geochim. Cosmochim. Acta 67, 3905-3923.

Richter F.M., Mendybaev R.A., Christensen J.N., Hutcheon I.D., Williams R.W., Sturchio N.C. and Beloso A.D., Jr. (2006) Kinetic isotopic fractionation during diffusion of ionic species in water. Geochim. Cosmochim. Acta 70, 277-289.

Robinson R.A. and Stokes R.H. (1959) Electrolyte Solutions, Butterworths, 571 p. Rodushkin I., Stenberg A., Andrén H., Malinovsky D. and Baxter D.C. (2004) Isotopic fractionation during diffusion of transition metal ions in solution. Anal. Chem. 76, 2148-2151.

Schloemer S. and Krooss B.M. (2004) Molecular transport of methane, ethane and nitrogen and the influence of diffusion on the chemical and isotopic composition of natural gas accumulations. Geofluids 4, 81-108.

Smith D.E. and Dang L.X. (1994) Computer simulations of $\mathrm{NaCl}$ association in polarizable water. J. Chem. Phys. 100, 3757-3766. 
Teng F.-Z., McDonough W.F., Rudnick R.L. and Walker R.J. (2006) Diffusion-driven extreme lithium isotopic fractionation in country rocks of the Tin Mountain pegmatite. Earth Planet. Sci. Lett. 243, 701-710.

Tsuchiyama A., Kawamura K., Nakao T. and Uyeda C. (1994) Isotopic effects on diffusion in $\mathrm{MgO}$ melt simulated by the molecular dynamics (MD) method and implications for isotopic mass fractionation in magmatic systems. Geochim. Cosmochim. Acta 58, 3013-3021.

Wasserman E., Wood B. and Brodholt J. (1995) The static dielectric constant of water at pressures up to $20 \mathrm{kbar}$ and temperatures to $1273 \mathrm{~K}$ : Experiment, simulations, and empirical equations. Geochim. Cosmochim. Acta 59, 1-6.

Watkins J.M., DePaolo D.J., Huber C. and Ryerson F.J. (2009) Liquid compositiondependence of calcium isotope fractionation during diffusion in molten silicates. Geochim. Cosmochim. Acta 73, 7341-7359.

Willeke M. (2003) Limits of the validity of the mass ratio independence of the StokesEinstein relation: molecular dynamics calculations and comparison with the Enskog theory. Mol. Phys. 101, 1123-1130.

Wilson M.A., Pohorille A. and Pratt L.R. (1985) Molecular dynamics test of the Brownian description of $\mathrm{Na}^{+}$motion in water. J. Chem. Phys. 83, 5832-5836.

Wolynes P.G. (1978) Molecular theory of solvated ion dynamics. J. Chem. Phys. 68, 473483.

Yamaguchi T., Matsuoka T. and Koda S. (2005) Molecular dynamics simulation study on the transient response of solvation structure during the translational diffusion of solute. J. Chem. Phys. 122, 014512. 
TABLE 1. Compilation of experimental and MD simulation values of $\beta$ (from Eq. 1) for monoatomic solutes diffusing in liquid water. Isotope fractionation results reported with unspecified confidence intervals (Chakrabarti, 1995; Rodushkin et al., 2004) were not included in Table 1. Simulation values of $\beta$ were obtained by linear regression of $\log D$ vs. $\log m$ as in Fig. 1. Reported $\beta$-values were obtained at $348 \mathrm{~K}$ (for ionic solutes) or $298 \mathrm{~K}$ (for noble gases) unless otherwise specified.

\begin{tabular}{|c|c|c|}
\hline Solute & $\beta$ (experiment) & $\beta$ (MD simulation) \\
\hline \multicolumn{3}{|c|}{ Divalent ions } \\
\hline $\mathrm{Mg}^{2+}$ & $0 \pm 0.0015^{\mathrm{a}}$ & $0.006 \pm 0.018^{\mathrm{b}}$ \\
\hline $\mathrm{Ca}^{2+}$ & $0.0045 \pm 0.0005^{\mathrm{c}}$ & $0.0000 \pm 0.0108^{\mathrm{c}}$ \\
\hline \multicolumn{3}{|c|}{ Monovalent ions } \\
\hline $\mathrm{Li}^{+}$ & $\begin{array}{l}0.0148 \pm 0.0017^{\mathrm{a}} \\
0.023 \pm 0.013^{\mathrm{d}}\end{array}$ & $0.0171 \pm 0.0159^{\mathrm{b}}$ \\
\hline $\mathrm{Na}^{+}$ & $0.023 \pm 0.023^{\mathrm{e}}$ & $0.029 \pm 0.022^{\mathrm{c}}$ \\
\hline $\mathrm{K}^{+}$ & $0.042 \pm 0.002^{\mathrm{c}}$ & $0.049 \pm 0.017^{\mathrm{c}}$ \\
\hline $\mathrm{Cs}^{+}$ & & $0.030 \pm 0.018^{\mathrm{c}}$ \\
\hline $\mathrm{Cl}^{-}$ & $\begin{array}{l}0.0258 \pm 0.0144^{\mathrm{a}} \\
0.0296 \pm 0.0027^{\mathrm{f}}\end{array}$ & $0.034 \pm 0.018^{b}$ \\
\hline $\mathrm{Br}^{-}$ & $0.0320 \pm 0.0097^{\mathrm{f}}$ & \\
\hline \multicolumn{3}{|c|}{ Noble gases } \\
\hline $\mathrm{He}$ & $0.492 \pm 0.122^{\mathrm{g}}$ & $0.171 \pm 0.028^{\mathrm{h}}$ \\
\hline $\mathrm{Ne}$ & & $0.150 \pm 0.018^{\mathrm{h}}$ \\
\hline $\mathrm{Ar}$ & & $0.078 \pm 0.024^{\mathrm{h}}$ \\
\hline $\mathrm{Xe}$ & & $0.059 \pm 0.023^{\mathrm{h}}$ \\
\hline
\end{tabular}

${ }^{a}$ Richter et al. (2006).

${ }^{\mathrm{b}}$ Bourg and Sposito (2007).

${ }^{\mathrm{c}}$ This study.

${ }^{\mathrm{d}}$ Estimated by Richter et al. (2006) from ${ }^{6} \mathrm{LiCl}$ and ${ }^{7} \mathrm{LiCl}$ electrolyte conductance measurements at $298 \mathrm{~K}$ reported by Kunze and Fuoss (1962).

${ }^{\mathrm{e}}$ Calculated by Richter et al. (2006) from $D\left({ }^{24} \mathrm{Na}^{+}\right) / D\left({ }^{22} \mathrm{Na}^{+}\right)$measurements at $298 \mathrm{~K}$ reported by Pikal (1972). 
${ }^{\mathrm{f}}$ Average of $D_{i} / D_{j}$ measurements reported by Eggenkamp and Coleman (2009) for $T=$ 275 to $353 \mathrm{~K}$.

${ }^{\mathrm{g}}$ Jähne et al. (1987); quantum isotope effects may contribute significantly to the measured fractionation of He isotopes (Bourg and Sposito, 2008).

${ }^{\mathrm{h}}$ Bourg and Sposito (2008). 
TABLE 2. Solvation properties of aqueous solutes during $2 \mathrm{~ns}$ MD simulations at $298 \mathrm{~K}$ : location $r_{\max }$ of the first peak in the solute-water $\mathrm{O}$ radial distribution function $g_{\mathrm{O}}$, solute coordination number $n_{\mathrm{O}}$ (the average number of water molecules located closer to the solute than the first minimum of $g_{\mathrm{O}}$ ), and average residence time $\tau_{\mathrm{S}}$ of water molecules in the first solvation shell of the solute. Residence time $\tau_{\mathrm{S}}$ was calculated as described by Koneshan et al. (1998b) with first shell size estimated as $r_{\max }$ plus the radius of a water molecule $(1.4 \AA)$. [Calculations of $\tau_{\mathrm{S}}$ sometimes allow water excursions out of the first solvation shell for durations less than 2 ps (Impey et al., 1983); we allowed no such excursions, a method that gives $\sim 10-20 \%$ smaller $\tau_{\mathrm{S}}$ values (Koneshan et al., 1998b).] The precision of our $r_{\max }$ estimates is $\pm 0.05 \AA$; confidence intervals on $n_{\mathrm{O}}$ were estimated by varying the location of the first minimum of $g_{\mathrm{O}}$ by $\pm 0.05 \AA$; confidence intervals on $\tau_{\mathrm{S}}$ were estimated by varying first shell size by $\pm 0.2 \AA$.

\begin{tabular}{|c|c|c|c|}
\hline Solute & $r_{\max }(\AA)$ & $n_{\mathrm{O}}$ & $\tau_{\mathrm{S}}(\mathrm{ps})$ \\
\hline \multicolumn{4}{|c|}{ Divalent ions } \\
\hline $\mathrm{Mg}^{2+}$ & 2.0 & $6.00 \pm 0.00$ & $>2,000^{\mathrm{a}}$ \\
\hline $\mathrm{Ca}^{2+}$ & 2.4 & $7.70 \pm 0.01$ & $193 \pm 19$ \\
\hline \multicolumn{4}{|c|}{ Monovalent ions } \\
\hline $\mathrm{Li}^{+}$ & 2.0 & $4.13 \pm 0.01$ & $71.3 \pm 1.8$ \\
\hline $\mathrm{Na}^{+}$ & 2.5 & $5.86 \pm 0.07$ & $19.4 \pm 0.1$ \\
\hline $\mathrm{K}^{+}$ & 2.8 & $7.39 \pm 0.31$ & $5.5 \pm 0.3$ \\
\hline $\mathrm{Cs}^{+}$ & 3.1 & $8.69 \pm 0.50$ & $4.0 \pm 0.4$ \\
\hline $\mathrm{Cl}^{-}$ & 3.2 & $7.23 \pm 0.28$ & $8.4 \pm 0.2$ \\
\hline \multicolumn{4}{|c|}{ Noble gases } \\
\hline $\mathrm{He}$ & 3.0 & $14.0 \pm 0.7$ & $1.3 \pm 0.2$ \\
\hline $\mathrm{Ne}$ & 3.1 & $15.7 \pm 0.8$ & $1.8 \pm 0.4$ \\
\hline $\mathrm{Ar}$ & 3.5 & $18.5 \pm 0.8$ & $2.8 \pm 0.6$ \\
\hline $\mathrm{Xe}$ & 3.9 & $22.3 \pm 1.0$ & $3.6 \pm 0.7$ \\
\hline
\end{tabular}


List of Figures.

Fig. 1. Diffusion coefficients of $\mathrm{Li}^{+}$(Bourg and Sposito, 2007), $\mathrm{Na}^{+}, \mathrm{K}^{+}, \mathrm{Cs}^{+}$, and $\mathrm{Ca}^{2+}$ isotopes in liquid water at $348 \mathrm{~K}$ obtained by MD simulation for a range of hypothetical isotopes with $m$ varying from 2 to $133 \mathrm{Da}$, plotted as $\log D$ vs. $\log m$. Each symbol represents a 2 ns block of each 8 ns simulation for alkali metals or a 4 ns block of each 16 ns simulation for $\mathrm{Ca}^{2+}$. Dashed lines show linear regression of the simulation results.

Fig. 2. Experimentally determined isotopic fractionation of $\mathrm{K}$ and $\mathrm{Ca}$ isotopes during salt diffusion between a small source sphere and a large outer container, plotted as 1000 $\ln \left(R_{i j} / R_{i j, 0}\right)$ vs. $-\ln f_{j}:(\mathrm{a}){ }^{41} \mathrm{~K} /{ }^{39} \mathrm{~K}$ fractionation in the source sphere and outer container (upper and lower parts of Fig. 2a, respectively) during $\mathrm{KCl}$ diffusion; (b) ${ }^{44} \mathrm{Ca} /{ }^{40} \mathrm{Ca}$ fractionation in the source sphere during $\mathrm{CaCl}_{2}$ diffusion. Mass-balance calculations based on $V_{\mathrm{c}} / V_{\mathrm{s}}=375$ and fitted $D_{i} / D_{j}$ ratios are shown as solid lines. The dashed line in Fig. $2 \mathrm{~b}$ was calculated with Eq. 2 (i.e., with the concentration in the outer container remaining negligible compared to that in the source sphere, which could have been the case in some experiments if the outer container became stratified because of water containing diffused salt sinking to the bottom of the container).

Fig. 3. Plot of $\beta$-values for monoatomic solutes in liquid water as a function of solute radius $r$, calculated as the first-peak distance $r_{\max }$ in the solute-water $\mathrm{O}$ radial distribution function minus the radius of a water molecule $(1.4 \AA)$. Experimental (triangular symbols) and MD simulation results (circular symbols) are from Table 1 . The $\beta$-values 
of $\mathrm{Cl}^{-}$obtained by Kunze and Fuoss (1962) and Eggenkamp and Coleman (2009) are not shown for clarity. The first-peak distance of the $\mathrm{Br}-\mathrm{O}$ radial distribution function was taken from Koneshan et al. (1998b). Shaded areas highlight the trends in $\beta$ vs. $r$ for uncharged, monovalent, and divalent solutes.

Fig. 4. Memory function $K(t)$ for five hypothetical isotopes of $\mathrm{K}^{+}(m=3$ to $100 \mathrm{Da})$ diffusing in liquid water at $348 \mathrm{~K}$, plotted as $K(t)$ vs. $\log t$.

Fig. 5. Plot of $\beta$-values for monoatomic solutes in liquid water as a function of the inverse of the residence time $\tau_{\mathrm{S}}(\mathrm{ps})$ of water molecules in the first solvation shell at 298 $\mathrm{K}$ (from Table 1). 


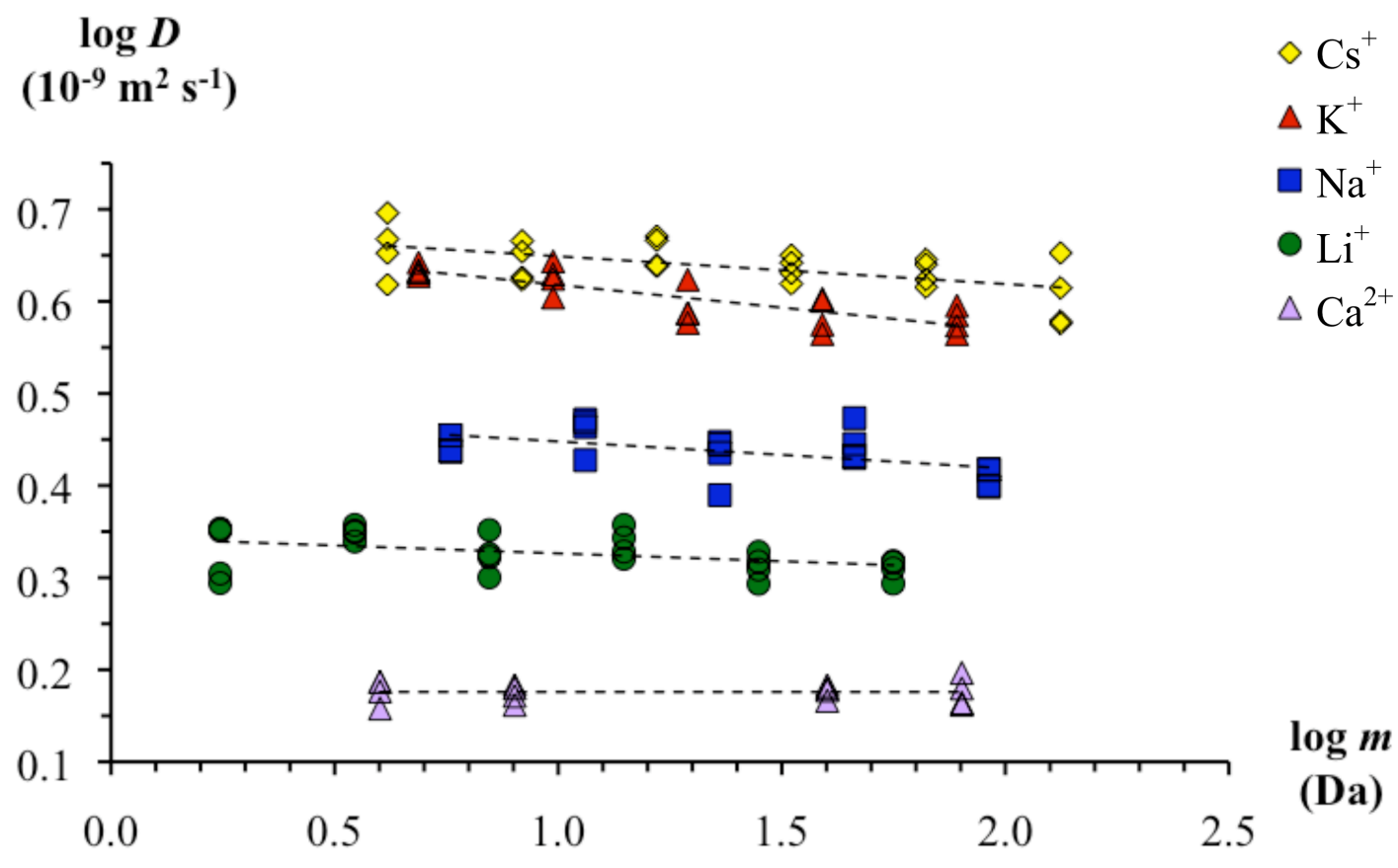

Figure 1. 
(a)

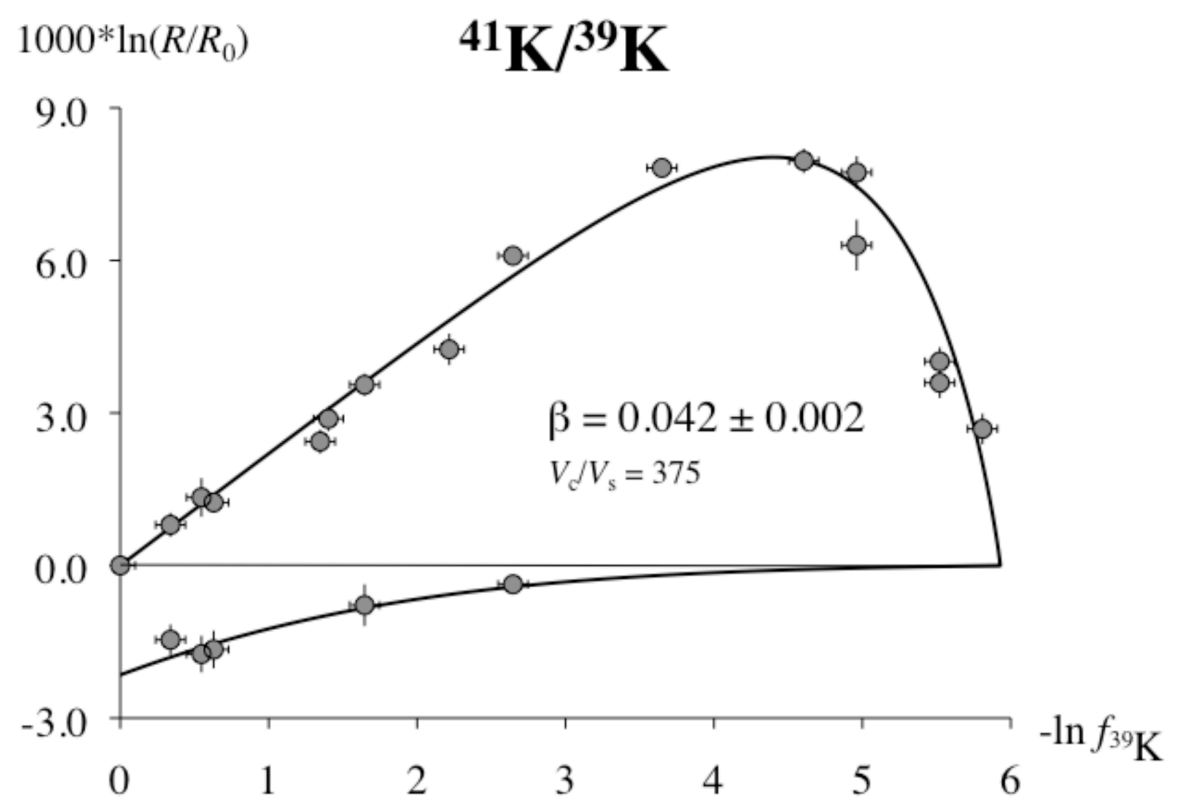

(b)

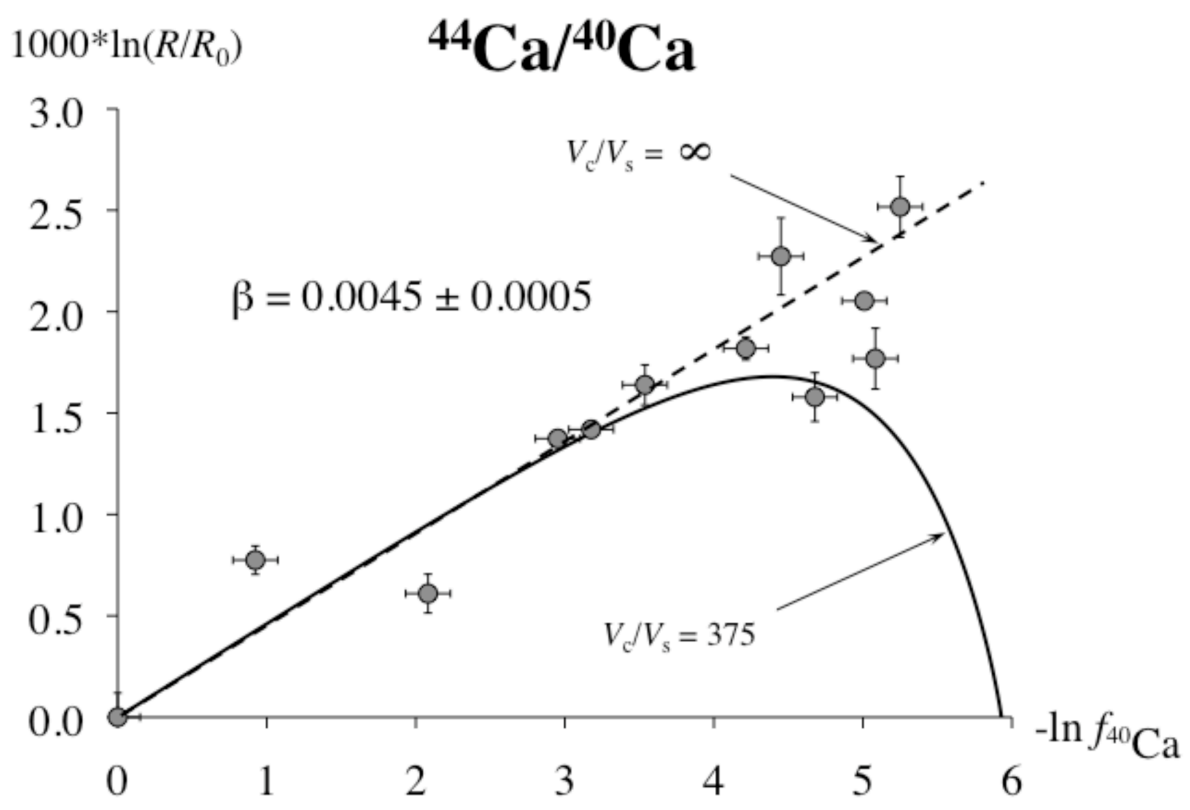

Figure 2. 


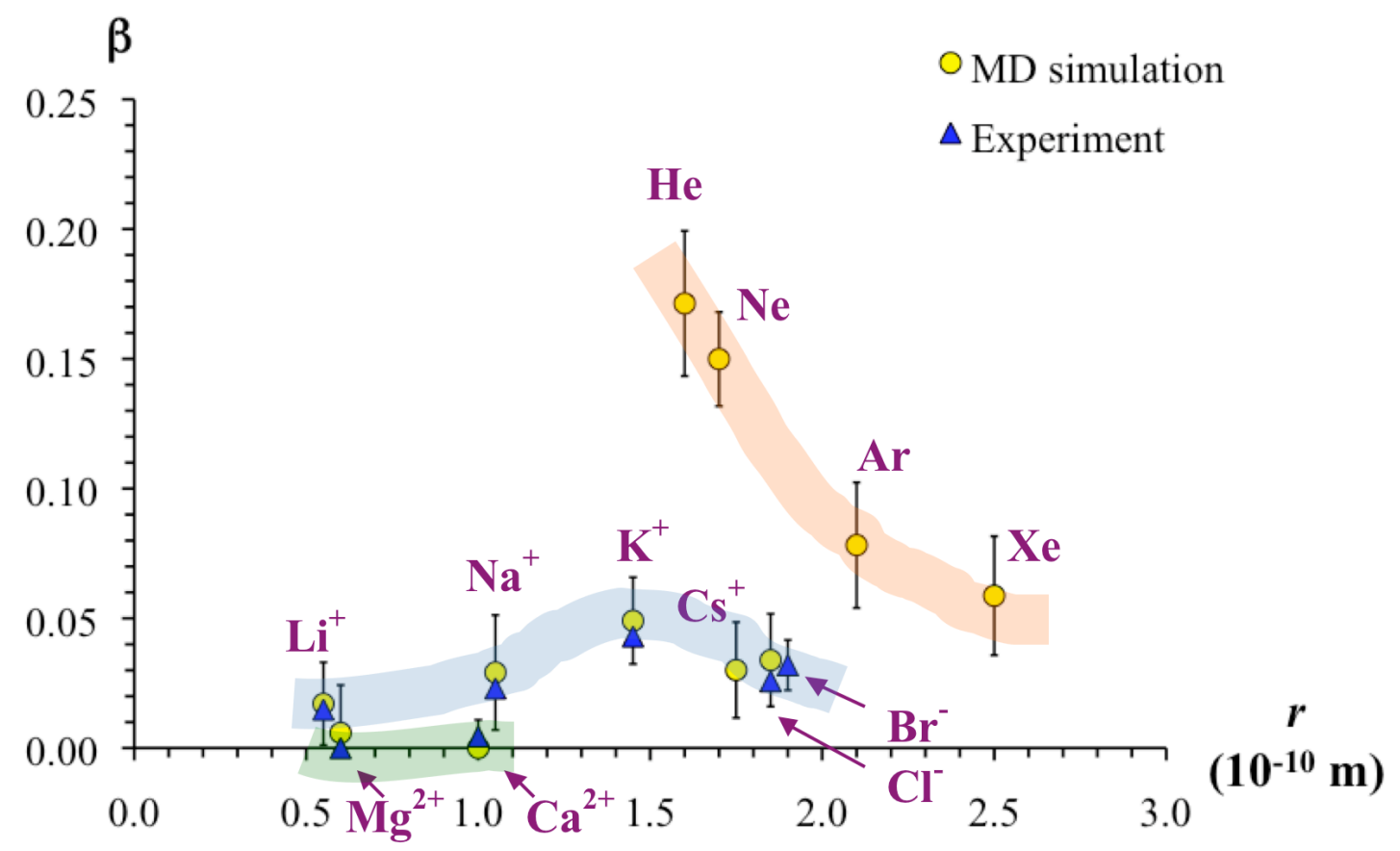

Figure 3. 


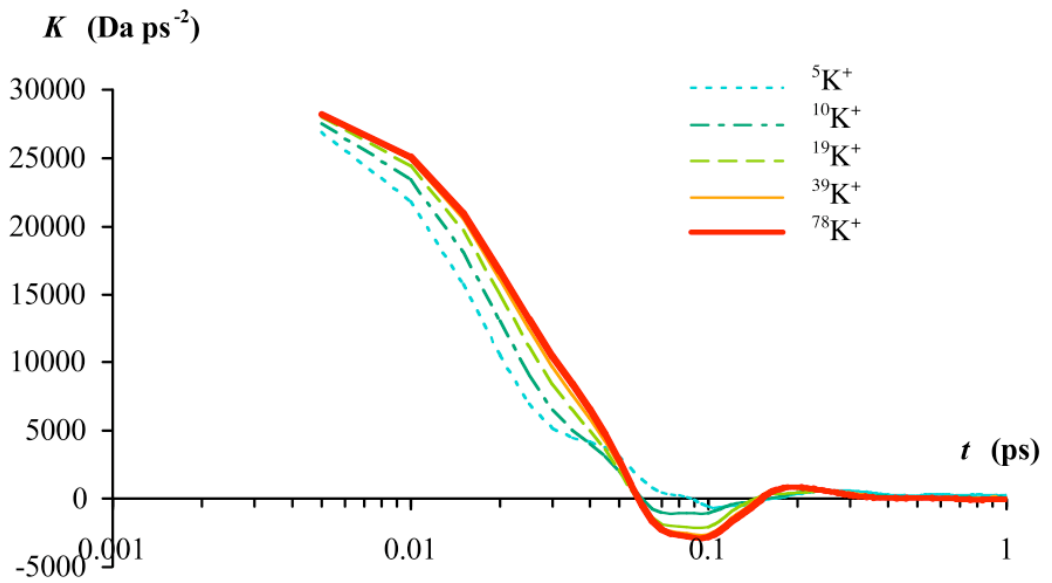

Figure 4. 


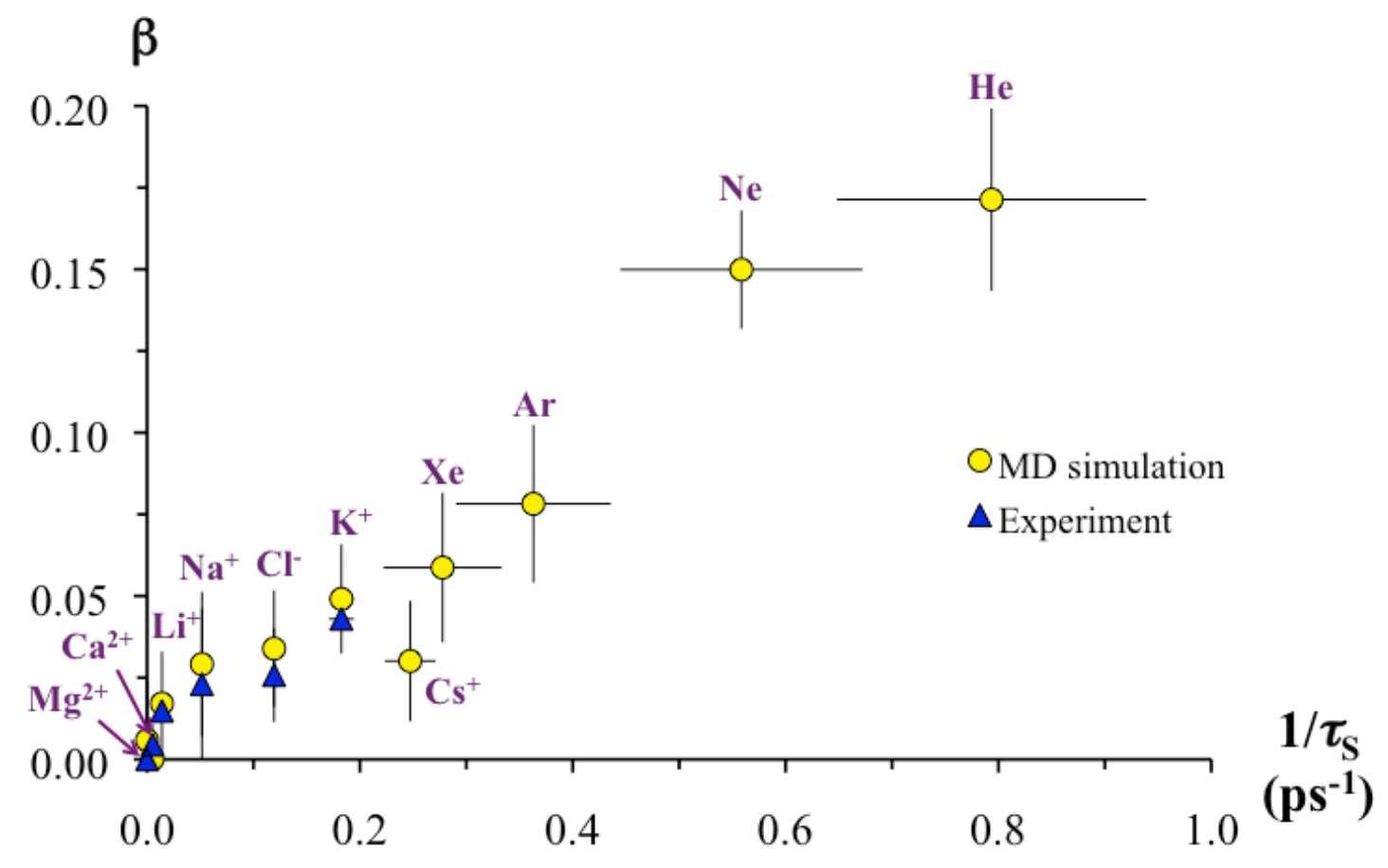

Figure 5. 